\title{
Morphometric Study of the Atlas Vertebra using Manual Method
}

\author{
Shilpa N Gosavi, MS Anatomy, Vatsalaswamy P*, MS Anatomy \\ Department of Anatomy, Padmashree D V V P F Medical College, Ahmednagar, India \\ *Department of Anatomy, Padmashree Dr D Y Patil Medical College, Pimpri, India
}

\begin{abstract}
The atlas (first cervical vertebra) has undergone many structural modifications. It is critically located and close to the 'life centres'. For this study, one hundred dried intact human atlas vertebrae from the Indian population were measured using a digital Vernier calliper that provides accurate resolution up to $0.01 \mathrm{~mm}$. The distance between the tips of the transverse process, the outer and the inner distance between the foramen transversaria and various diameters of vertebral foramen were measured. The mean width of the measured atlases was $69.37 \mathrm{~mm}$. The mean distance between the lateral margins of foramen transversaria was $55.66 \mathrm{~mm}$ and the inner distance was $45.93 \mathrm{~mm}$. The mean thickness of vertebral artery grooves was $3.72 \pm 1.06 \mathrm{~mm}$. The observations made in the present study may help in improving understanding of various bony dimensions while operating close to important structures like nerve roots and the vertebral artery.
\end{abstract}

Key Words:

Atlas, Atypical cervical vertebra, C1, morphology

\section{INTRODUCTION}

The atlas vertebra has many unique features. It is located at a critical point close to the vital centres of the medulla oblongata, which can get compressed by a dislocation of the atlanto-axial complex or instability of atlanto-occipital joint. Therefore, reduction and rebuilding of the stability of this complex is important. A short segment posterior fixation technique is often adopted to preserve the motion of the atlanto-occipital joint ${ }^{1}$. Hence the aim of the present study was to evaluate the metrical details of the atlas in the Indian population.

\section{MATERIALS AND METHODS}

One hundred dried human atlases of unknown sex, obtained from the Department of Anatomy of four medical colleges were studied. All samples were drawn from the Indian population. Atlases with pathological features were excluded from the study. The following parameters were measured for each atlas using a digital Vernier calliper that provides accurate resolution up to $0.01 \mathrm{~mm}$. Each measurement was taken three times to minimize error. All measurements were performed by the first author for the sake of consistency.

The distance between the tips of the transverse processes of the atlas (atlas width, TD), the distance between the most lateral margins of the two foramina transversaria (outer distance, OD), and the distance between the medial margins of the two foramina transversaria (inner distance, ID) were all measured. The maximum anteroposterior (A-P) diameter of the vertebral foramen was measured in the sagittal plane and the minimum A-P diameter was measured in the parasagittal plane. The maximum transverse diameter of the vertebral foramen was measured and the shape, anteroposterior and transverse diameters of the superior articular facet as well as of the inferior articular facet were noted bilaterally.

We also measured the thickness of the posterior arch at the groove for the vertebral artery on both sides. The height of the anterior as well as posterior arches in the midline was measured from its superior border to its inferior border. The vertical height of the facet of the dens was measured as the maximum vertical distance at midline, and the maximum transverse width of the facet of the dens was measured as the maximum transverse distance. The mean, range and standard deviation were calculated for all measurements for the 100 vertebrae. Significant difference was calculated using the $\mathrm{Z}$ test and $\mathrm{p}<=0.05$.

\section{RESULTS}

Fifteen parameters were studied for the hundred atlases. Measurement results were analysed and are shown in Tables I, II and III.

The mean width of the atlases was $69.37 \mathrm{~mm}$ (Table I), and the mean thickness of the vertebral artery groove was 3.72 $\mathrm{mm}$ on the right side and $3.70 \mathrm{~mm}$ on the left side (Table III) The superior articular facet was oval in $74 \%$ of the atlases with the anteroposterior diameter larger than the transverse diameter in the majority of samples, whereas the facets of

Corresponding Author: Shilpa N Gosavi, Dept. of Anatomy, Padmashree Dr Vitthalrao Vikhe Patil Foundation's Medical College, Vilad ghat, Ahmednagar, India

Email: sngosavi@yahoo.com 
Table I: Anatomical parameters of atlas

\begin{tabular}{|c|c|c|c|}
\hline No. & Parameter & Range $(\mathrm{mm})$ & $\begin{array}{c}\text { Mean } \pm \text { SD } \\
(n=100)(\mathrm{mm})\end{array}$ \\
\hline 1 & Width of Atlas & $56.36-85.02$ & $69.37 \pm 6.47$ \\
\hline 2 & Outer distance $\mathrm{b} / \mathrm{w}$ lateral margins of foramina transversaria (OD) & $45.36-69.35$ & $55.66 \pm 5.01$ \\
\hline 3 & Inner distance b/w medial margins of foramina transversaria (ID) & $36.25-55.29$ & $45.93 \pm 4.22$ \\
\hline \multirow[t]{3}{*}{4} & Vertebral foramen $\quad$ Trans*. diameter & $22.81-32.76$ & $26.89 \pm 1.93$ \\
\hline & A-P maximum & $22.62-36.56$ & $27.89 \pm 2.59$ \\
\hline & A-P minimum & $20.14-35.1$ & $25.66 \pm 2.59$ \\
\hline
\end{tabular}

*Trans. - Transverse

Table II: Diameters of articular facets of atlas

\begin{tabular}{|lccccc|}
\hline Parameter & Diameter & \multicolumn{2}{c}{ Range $(\mathbf{m m})$} & \multicolumn{2}{c|}{ Mean \pm SD $(\mathbf{n}=100)(\mathbf{m m})$} \\
& & Rt. & Lt. $\boldsymbol{\text { Rt. }}$ & Lt. \\
\hline Superior articular facet & A -P & $14.03-27.26$ & $15.57-27.3$ & $21.24 \pm 2.39$ & $21.02 \pm 2.52$ \\
& Transverse & $6.75-14.5$ & $6.87-14.21$ & $10.36 \pm 1.72$ & $10.47 \pm 1.61$ \\
Inferior articular facet & A-P & $10.62-20.62$ & $9.89-21.82$ & $16.57 \pm 1.91$ & $16.50 \pm 1.67$ \\
& Transverse & $7.13-17.56$ & $7.4-17.53$ & $14.01 \pm 1.93$ & $14.42 \pm 1.67$ \\
\hline
\end{tabular}

* - Right, $\uparrow$ - Left

Table III: Dimensions of some parameters of atlas

\begin{tabular}{|llccc|}
\hline No. & Parameter & Range $(\mathbf{m m})$ & $\begin{array}{c}\text { Mean } \pm \text { SD }(\mathbf{n}=\mathbf{1 0 0}) \\
(\mathbf{m m})\end{array}$ \\
\hline 1 & Thickness of groove & Rt* & $2.0-6.42$ & $3.72 \pm 1.06$ \\
& for Vertebral artery & Lt† & $1.18-7.28$ & $3.70 \pm 1.06$ \\
2 & Anterior arch height & $6.88-16.19$ & $10.33 \pm 1.67$ \\
3 & Posterior arch height & $4.88-14.11$ & $8.61 \pm 1.77$ \\
4 & Height of facet for dens & $2.1-14.11$ & $8.91 \pm 2.34$ \\
5 & Width of facet for dens & $5.21-15.34$ & $9.37 \pm 2.19$ \\
\hline
\end{tabular}

Table IV: Diameters of articular facets of atlas

\begin{tabular}{|c|c|c|c|c|c|c|}
\hline & \multirow[t]{2}{*}{ Parameter } & \multicolumn{4}{|c|}{ Previous studies } & \multirow[t]{2}{*}{ Present study } \\
\hline & & $\begin{array}{l}\text { Senegul \& } \\
\text { Kodiglu }^{2}\end{array}$ & Lang $^{7}$ & $\begin{array}{l}\text { Heggeness \& } \\
\text { Doherty }^{5}\end{array}$ & $\begin{array}{c}\text { Cacciola } \\
\text { et al. }{ }^{6}\end{array}$ & \\
\hline 1 & Width of Atlas & 74.6 & 78.2 & & & 69.37 \\
\hline 2 & Outer distance b/w outer & & & & & \\
\hline & margins of $f$. transversarium & 59.5 & 64 & & & 55.66 \\
\hline 3 & Inner distance $\mathrm{b} / \mathrm{w}$ inner margins & & & & & \\
\hline & of $\mathrm{f}$. transversarium & 48.6 & 52.3 & & & 45.93 \\
\hline \multirow[t]{2}{*}{4} & \multirow{2}{*}{ Vertebral foramen } & 28.7 & 30.2 & 32 & & 26.89 \\
\hline & & 46.2 & 34.5 & 29 & & 27.89 \\
\hline \multirow[t]{2}{*}{5} & Superior & 19.2 & & & 19.73 & 21.02 \\
\hline & articular facet & 9.7 & & & 11.12 & 10.47 \\
\hline \multirow[t]{2}{*}{6} & Inferior articular & 17.3 & & & 15.76 & 16.50 \\
\hline & Transverse & 14.6 & & & 15.22 & 14.42 \\
\hline
\end{tabular}

* - Transverse diameter, $\uparrow$ - maximum

$26 \%$ were kidney shaped. The anterior edge of these facets was nearer to the midline than to their posterior edge. Their diameters are posted in Table II. There was not a statistically significant difference when comparing diameters. The shape of the inferior articular facet was circular in $71 \%$ and oval in $29 \%$ of atlases. The mean anterior arch height was $10.33 \pm$ $1.67 \mathrm{~mm}$ and the mean height of the posterior arch was 8.61 $\pm 1.77 \mathrm{~mm}$. (Table III)

\section{DISCUSSION}

The atlas supports the skull and is uniquely positioned in the atlantoaxial complex. As new surgical techniques and instruments for the treatment of unstable cervical spine continue to evolve, detailed knowledge about this bone becomes even more essential ${ }^{2}$. Table IV gives a comparison of certain atlas parameters in previously published studies to the present study. From Table IV, it is clear that there is some difference in such values for various parameters. This 
variation is perhaps due to the difference in the races to which the atlases belonged. Textbooks of anatomy describe racial differences in bones, particularly the skull. It is therefore, not illogical to say that the differences noted above are due to racial differences in the atlas.

Cacciola et al. ${ }^{5}$ reported that in $76 \%$ of the vertebrae studied, the superior articular facet was oval in shape and kidney shaped in $24 \%$. Senegul and Kodiglu ${ }^{2}$ observed oval superior articular facets in $72 \%$ and kidney shaped in $28 \%$. As noted above, our measurements were similar regarding facet shape. Lang ${ }^{6}$ found that facets were sometimes completely divided into a larger anterior and a smaller posterior section; we found a similar variation in the two facets of the vertebrae bilaterally.

The inferior articular facets were flat or slightly concave facing medially and slightly backwards. In our study, 71\% were circular with similar A-P and transverse diameters and $29 \%$ were oval. Cacciola et $a l^{5}$. observed circular inferior articular facets in most vertebrae, and Senegul and Kodiglu ${ }^{2}$ also noted circular or slightly droplet shaped facets. The groove on the superior surface of the posterior arch of atlas represents the exact location of the vertebral artery ${ }^{2}$. The mean thickness of this groove was $3.72 \pm 1.06 \mathrm{~mm}$ in the present study, whereas Senegul and Kodiglu ${ }^{2}$ reported thickness $5.05 \mathrm{~mm}$ and Ebraheim et al. ${ }^{7}$ as $4.1 \pm 1.2 \mathrm{~mm}$. Senegul and Kodiglu ${ }^{2}$ explained that this thickness is sufficient for some fixation techniques such as clamp and hook plating and atlanto-axial wiring. Tan et al. ${ }^{8}$ reported groove thickness of $4.65 \mathrm{~mm}$ in their study on manual and radiological measurements of fifty isolated atlases. In four of their cases (8\%), the groove was less than $4 \mathrm{~mm}$ in thickness. In the present study, there were 65 cases in which the thickness was $<4 \mathrm{~mm}$.
In their study on cadaveric specimens and dry bones Cacciola et $a l .{ }^{5}$ observed that the groove for the vertebral artery was completely converted into a foramen only in one out of twenty sides. In our study on hundred atlases such a foramen was observed on the right side in two and bilaterally in one.

\section{CONCLUSION}

We studied one hundred dried atlas vertebrae deriving from the Indian population to give us the opportunity to analyse metrical data. The mean width of the atlas was $69.37 \mathrm{~mm}$ in the present study. The thickness of the vertebral artery groove was $3.72 \mathrm{~mm}$ on the right side and $3.70 \mathrm{~mm}$ on the left side. The observations made in the present study may be helpful to neurosurgeons who routinely operate close to important structures such as nerve roots and vertebral artery in the atlanto-occipital area.

\section{ACKNOWLEDGEMENT}

We are grateful to Dr. B. R. Zambare, Head of the Department, Dept. of Anatomy, P.D.V.V.P.F. Medical College, Ahmednagar, for his continuous support and encouragement. We are in debt to Dr. V. R. Mysorekar, former Head of the Department of Anatomy of various medical colleges, for his valuable suggestions and help in the preparation of this manuscript.

\section{REFERENCES}

1. Hanson PB, Montesano PX, Sharkey NA et al. Anatomic and biochemical assessment of transarticular screw fixation for the atlanto-axial instability. Spine. 1991; 16: 1141-5.

2. Senegul G, Kodiglu HH. Morphometric anatomy of atlas and axis vertebra. Turkish Neurosurgery. 2006; 16(2): 69-76.

3. Lang J. Craniocervical region, osteology and articulations. Neuro Ortho. $p$ 1986; 1:67-92

4. Heggeness MH, Doherty BJ. The quantitative anatomy of the atlas. Spine. 1994; 19:2497- 500.

5. Cacciola F, Phalke U, Goel A. Vertebral artery in relationship to C1 -C2 vertebra: An anatomic study. Neurology India. 2004; 52(2): 178-84.

6. Lang J, Editor, Skull Base and Related structures. Struttgart, Schattauer, 1995; 292.

7. Ebraheim NA, Xu R, Lin D, Ahmad M, Heck BE. The quantitative anatomy of the vertebral artery groove of atlas and its relation to the posterior atlanto-axial approach. Spine. 1998; 23: 320-3.

8. Tan M, Wang H, Wang Y, Zang G, Yi P, Li Z, and Yang F. Morphometric evaluation of screw fixation in Atlas via posterior arch and lateral mass. Spine. 2003; 28(9): 888-95. 